\title{
Our first First Nations physician
}

\author{
Bridging Two Peoples: Chief Peter E. Jones, \\ 1843-1909
}

Allan Sherwin

Wilfrid Laurier University Press; 2012.

$\mathrm{P}$ eter Edmund Jones graduated in 1866 as a physician from Queen's University in Kingston, Ontario. He was the first status Native Canadian to graduate from a Canadian medical school. Jones, or Kahkewaquonaby II (Waving Plume), not only practised medicine in southwestern Ontario throughout the Victorian era, he went on to become head chief of his band, secretary-general of the Grand General Indian Council of Ontario and Quebec, publisher of the first Aboriginal newspaper (The Indian) and a federal Indian agent appointed by Sir John A. MacDonald. This richly detailed, sensitive and generally wellresearched biography is based on personal letters and diaries, historical manuscripts and official government documents. Author, Dr. Allan Sherwin, professor emeritus of neurology at McGill University in Montréal, Que., describes the many professional roles and contributions of Jones, illustrating how Jones sought to fulfill his life goal of bridging the two cultures he inhabited.

Jones' family heritage was WelshAmerican and Mississauga Ojibwe. Outwardly, he was non-white, but with his Christian education and Methodist faith, Jones was inwardly white. Jones often felt that he belonged to neither group. As a medical student, he learned about the prevailing clinical theories and practices of Western biomedicine, yet his MD thesis, now sadly lost, was entitled "The Indian Medicine-Man.” As a practising doctor, Jones sought to alleviate diseases on reserves through vaccination programs and he engaged in other public health activities, such as preventing garbage accumulation around homes and ensuring the availability of potable water. Jones also tried to reduce the incidence of tuberculosis, especially in children, but his application of "scientific" principles

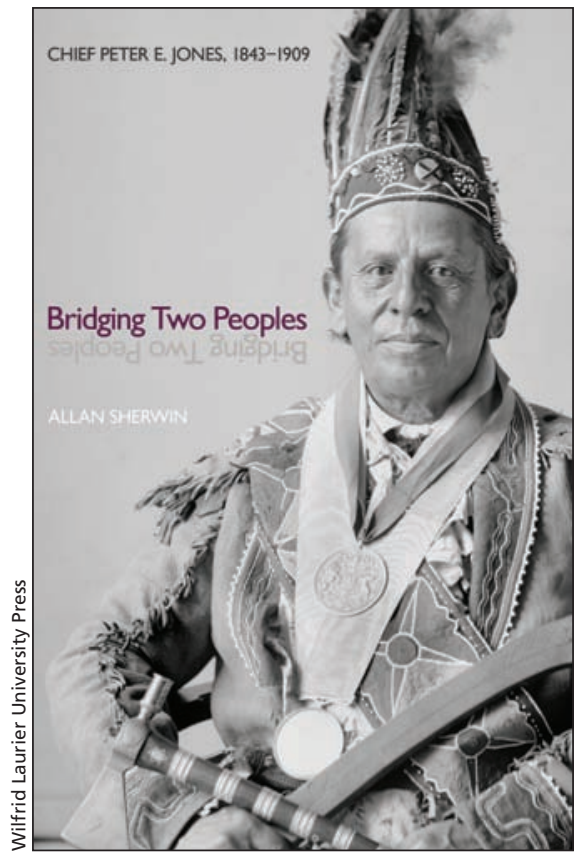

were in tension with those used by his cousin, George Henry Jr. The latter styled himself, as the Medicine Man of the Mississaugas of New Credit, selling commercial cure-alls based on traditional native recipes.

Another instance of cultural conflict arose when, as an Indian agent for the federal government, Jones found himself embroiled in a land-claim dispute. Sherwin notes, "Jones found himself caught between his loyalty to the members of his own band and his loyalty to his oath to follow the orders of his employer, the government of Canada." Even more frustrating for Jones was the reverse racial slur flung at him in 1885 by the Toronto Globe, referring to him as "an almost full-blooded white." Bridging two peoples, then, was a precarious balancing act.

In the end, biographers are bound to evaluate their subject. Sherwin concludes that Jones made mistakes, especially by trying to lead his people but not from within the reserve. Jones was perhaps an "outsider" and a "romantic," yet he pushed for democratic freedoms for his people and tried to educate them about the power of their newly gained fran- chise. Thus, "Jones's contributions to Aboriginal self-governance are considerable," Sherwin concludes. He was also deeply committed to the delivery of health care to his people. As a historian, I believe this book to be a most worthwhile contribution to the historiography of Canadian medicine; it also joins the growing literature on indigenous studies. Those interested in learning more about both these fields of study might wish to complement Bridging Two Peoples by reading Kristin Burnett's Taking Medicine: Women's Healing Work and Colonial Contact in Southern Alberta, 1880 1930 (2010) and Maureen Lux's Medicine that Walks: Disease, Medicine, and Canadian Plains Native People, 1880-1940 (2001).

Recalling that Jones was the first status Native Canadian to graduate from a Canadian medical school almost 150 years ago, I was compelled, as a historian at a medical school, to reflect on current trends respecting indigenous students and medical education. A 2008 report by the Indigenous Physicians Association of Canada and the Association of Faculties of Medicine of Canada indicates that most of Canada's 17 faculties of medicine have policies in place that encourage Aboriginal applicants. Many also have designated seats, but it appears that only two schools (the University of British Columbia and the Northern Ontario Medical School) deal specifically with Aboriginal health issues. Thus, the Peter Joneses of today may have greater opportunity to be admitted to medical school, but the crucial matter identified by Sherwin in his study still exists: how to bridge two peoples, especially within the medical context.

\section{J.T.H. Connor PhD}

Professor of Medical Humanities and History of Medicine Faculty of Medicine Memorial University St. John's, NL

CMAJ 2014. DOI:10.1503/cmaj.122078 